\title{
Perspective
}

\section{Human-animal Hybrid Embryo Experiment Gospel versus Disaster?}

Morgan Springer, Ph.D.; Fuzhou Wang, M.D., Ph.D.; Juan H. Jersey, Ph.D.; Donne Will, Ph.D., M.P.H.

\section{SUMMARY}

The academic debate on the study of human and animal embryos has never stopped. Despite the great expectations of scientists, the human-animal embryo hybrid experiment costs a lot and requires high technology as the endorsement, and is highly questioned internationally. Human and animal embryo experiments are contrary to ethics, and the results of cross-species hybrid embryos are unpredictable, or cause zoonotic diseases or human catastrophe. The human and animal parts of the human "chimera" embryo will develop independently, and the DNA of the two will not be mixed. It is still far from being able to use the organs obtained from the mixed embryos of humans and animals to carry out organ transplants to save more lives.

\section{KEYWORDS}

Human-animal Embryo Hybridization; Organ Transplantation; Ethical Debate; Human Future

Sci Insigt. 2019; 30(1):58-62. doi:10.15354/si.19.pe030.

Author Affiliations: Author affiliations are listed at the end of this article.

Correspondence to: Dr. Morgan Springer, Ph.D., Email: morgan.springer@basehq.org

Dr. Fuzhou Wang, M.D., Ph.D., Email: fred.wang@basehq.org

Dr. Juan H. Jersey, Ph.D., Email: juan.jerey@basehq.org

Dr. Donne Will, Ph.D., M.P.H., Email: donne.will@basehq.org

The BASE, Chapel Hill, NC 27510, USA.

Copyright (C) 2019 The BASE. This is an open access article distributed under the Creative Commons Attribution License, which permits unrestricted use, distribution, and reproduction in any medium, provided the original work is properly cited. 
When the science-fiction shines into reality, there is a panic in surprise.

A CCORDING to the Spanish newspaper El Pais, a multinational research team led by Spanish scientist Juan Carlos Izpisua Belmonte claimed that they have implanted human cells into monkey embryos and successfully cultivated the world's first human-monkey hybrid embryos (1). However, due to ethical concerns, the experiment was forced to terminate when the central nervous system was preparing to start to develop on the fourteenth day of the embryo. Belmonte said that if the experiment was not suspended, a human-monkey hybrid could have been born.

Shaped stem cells can be applied to human organ transplants in the future, which is a major breakthrough for medical development. However, many scientists pointed out that human-monkey embryos definitely against the ethical moral and that monkeys are likely to develop self-awareness after birth and eventually lead to self-destruction.

At present, although the experiment has been suspended, scientists have opened another door in the study of human and animal hybrids. The Japanese government just approved a groundbreaking experiment in July 2019 that allows animals to be used to cultivate human organs.

\section{THE HISTORICAL PROCESS OF HUMAN AND ANIMAL HYBRIDIZATION}

According to The Guardian, the experiment led by the Spanish genetics professor Belmonte aimed to create the human chimera, a single organism composed of cells of different genotypes (2). The team believed that one day in the future, specific organs that match human recipients can grow in animals. The method of cultivating is to take the cells from the adult body, re-edit them into stem cells, and then introduce them into the embryos of another animal.

Alejandro De Los Angeles, a stem cell biologist at Yale University, believes that cultivating human monkey embryos gives human hope that this technology can contribute to organ transplantation. This study can tell us which types of stem cells can be used to find ways to improve the efficiency of human and animal chimeras. London genetics scientist Robin Lovell-Badge opposed the study. He pointed out that it is difficult to control the contribution of human cells to organogenesis in ex- periments. Human monkey embryos are likely to produce self-awareness if they eventually produce a mixture of monkeys.

Regarding the details of the human monkey embryo experiment, the research team has not yet announced, but they have successfully cultivated human pig embryos. In January 2017, the team announced in the Cell that they injected human stem cells into pig embryos and successfully developed human pig chimeric embryos for the first time and developed them in pigs for three to four weeks (3). The paper showed that breeding chimeric embryos was divided into two stages. First, using the CRISPR technology known as "genetic scissors," deleted the key genes that form organs in pig embryos and create genetic "vacancies." In the second step, human induced pluripotent stem cells (iPS cells) were injected into the pig embryo.

iPS cells were obtained directly from human somatic cells and have the ability to differentiate into various types of cells as embryonic stem cells. At the time, Belmonte said that cultivating human pig embryos was an important step, but it was still a long way from the ultimate goal of cultivating transplantable organs. After more than two years, the team he led once again achieved a breakthrough.

After the successful breeding of human-pig embryos, in March 2018, scientists at Stanford University first cultivated human-sheep chimeras. Researchers imported human stem cells into sheep embryos and obtained human sheep chimeras. Pablo Ross, a zoologist who participated in the human-sheep chimera experiment, said: "We now have this magical life-saving technology (referred to as organ transplant), but it is not enough to help a person." He continued, "Imagine, what happens if you can develop a mature organ in nine months. These organs can be used not only to save lives, but also to treat other diseases such as diabetes" $(4,5)$.

On July 26, 2019, the journal Nature reported that the Japanese government approved the first hybrid embryo experiment. The research team led by Hiromitsu Nakauchi, a professor at the University of Tokyo and Stanford University, plans to grow human cells in mouse and rat embryos in August and then transplant them into surrogate animals (6). Nakauchi said that he plans to slowly carry out the current experiment and will not try to make any hybrid embryos full term for a while. First, he will culture hybrid mice and rat embryos to 14.5 and 15.5 days, respectively. He will then apply to breed hybrid embryos in pigs for up to 70 days. 
The experiment approved by Japan is different from the "human-animal hybrid". The research team injects a cell called iPS into the embryo of an animal that does not grow certain organs to check whether to grow the corresponding organs in this animal, and provide important data for the study of human organ transplantation.

According to the Asahi Shimbun, Nakauchi said, "After 10 years of preparation, we can finally begin serious research in this field." He pointed out that if experiments are carried out between the same species, the mixture of human organs will not be allowed due to ethical issue (7). In contrast, cultivating human internal organs in animals can also encounter ethical problems, but it is easier to achieve.

\section{HUMAN-ANIMAL EMBRYO HYBRIDIZATION IS THEORETICALLY CONDUCIVE TO ORGAN TRANSPLANTATION}

It has always been an attractive plan to mix human tissue and organs with the tissues and organs of animals and grow them in animals to extract organs for human transplantation or to treat diseases. The reason is that the human body donates fewer organs, and the resources derived from human living are also limited by technology and ethics. For example, when extracting donor stem cells, one needs a human leukocyte antigen matching, and most of them have the same or identical matching; second, it is necessary to comply with the ethical principles of the informed consent of both parties.

In order to break through these limitations, the cultivation of human or animal-bound embryos or organs is an attempt to reduce immune rejection and access to large amounts of biological resources (organs and tissues) for transplantation and treatment. The humananimal embryo test approved in Japan is an "animal polymerized embryo" in which fertilized eggs in mice are implanted into human iPS cells to produce humananimal cells. The embryo is then bred in the uterus of the animal, thereby producing larvae having organs such as human pancreas in the body. If such an organ can be obtained and transplanted for humans, it is theoretically possible to avoid immune rejection, and the pancreas grown in the animal can also be used to extract islet cells or insulin to treat diabetes.

\section{ETHICAL RISK FOR HUMAN-ANIMAL EMBRYO HYBRIDIZATION}

This kind of operation may theoretically lead to the advent of human and animal hybrids. Nakauchi said that he understands that the public is worried about the emergence of "human and animal hybrids" and will closely monitor the mouse fetus. Once it is found that its brain contains more than $30 \%$ of human cells, it will not be born. After the birth, it will be observed for a maximum of 2 years.

This involves the ethical issues of scientific research. In fact, in order to launch each research, we must first demonstrate the purpose, means, application scope and expected effects of the research, and at the same time assess whether the research is in line with human ethics. Finally, when the results of this study are to be used for commercial transformation and social use, it is also necessary to assess the benefit risk ( $\mathrm{B} / \mathrm{R}$ analysis) of the results of this study applied to society in order to determine whether the study is feasible and whether the results can be pushed to the market and society.

Whether

it is the current study in Japan

\section{CHIMERAS}

The name comes from Greek mythology, which described monstrous creatures that were part dragon, part goat, and part lion. Today's chimeras are organisms that contain cells from two different species. or the research of human and animal embryo hybridization in other countries, there are three purposes. One is to treat the disease, the other is to obtain more embryos for research (because human embryos are difficult to obtain), and the third is to determine the proportion of human genes in animals. In fact, only the first two of these three purposes are more convincing, so the government's medical regulatory agency may approve such research. But noble purpose does not mean that means must be beneficial to humans, biology and the environment. Specifically, human and animal embryos have different means of hybridization, and the risks to humans, organisms, and the environment are different, and the degree of ethical acceptance is different.

\section{WILL IT OPEN THE NEXT "PANDORA BOX”?}

In the past, the common method for hybridization of human and animal embryos was cytoplasmic hybridization, that is, the nucleus was first taken out from the egg 
cells of the animal, and then the human nucleus was transplanted into it, and the cell tissue was integrated by electric shock to produce a new cell. Since the nucleus (chromosome) of this new cell is derived from human egg cells, but contains a small amount of mitochondrial DNA (also belonging to genetic material) in the cytoplasm of the animal, the embryos generated by cytoplasmic hybridization contain most of the genetic code (99\%) belongs to humans, and less than $1 \%$ of genetic material comes from animals.

There are two other cases of biological hybridization. One is to fertilize the eggs of another animal with the sperm of one animal, so that the genes from the two animals in the fertilized egg are each half. Another type of hybridization is called a chimera, in which an embryonic cell of one animal is mixed with an embryonic cell of another animal to form a complete embryo.

The Japanese researchers' practice is to implant the iPS cells of the human body into the human body, similar to chimeras, but it is not clear how much the proportion of such embryonic chimera human and animal cells is. But either method is to combine or heterozygous the cells and tissues of humans and animals, and if new organisms are formed by embryonic combination, it is possible to form new species by inheritance, and the actual harm to humans cannot be Expected.

Although the Japanese side said that it can be controlled, as long as the mouse's brain is found to contain more than $30 \%$ of human cells, it will not be born, but the situation is constantly changing. As early as 2008, the British House of Commons passed the Artificial Insemination and Embryology Act (8) with an overwhelming majority of 355 votes to 129 votes, allowing human embryo research for medical research purposes.

However, today the British social and scientific community is more alert to such research and is delineating more restricted areas. The UK has banned the use of large primates for scientific experiments on humanbeast hybrids. In a report from the British Academy of Medical Sciences, the researchers proposed three particularly sensitive areas of animal testing: cognitive, reproductive, and human-specific. One of the cores of these three sensitive areas is the ban on the fusion of human and primate cells and genetic material.

In terms of fertility research, the UK does not allow the use of human eggs or sperm to produce animal embryos for more than 14 days. In addition, humanspecific abilities or characteristics such as language and human appearance are also prohibited areas that should not be crossed in animal experiments.

Human and animal embryo hybridization can of course be studied, but there must be restrictions and exclusion zones, and more importantly, a benefit risk assessment should be performed when applying such findings. What kind of results will be obtained in such a future research, and it needs to be closely monitored. Otherwise, science will bring to humanity not the gospel, but may be a disaster.

\section{ARTICLE INFORMATION}

\begin{abstract}
Author Affiliations: Group of Genetic Biol ogy, Division of Biology and Chemistry (Springer), Group of Neuropharmacology and Neurophysiology, Division of Neuroscience (Wang), Group of Embryology, Division of Medicine and Public Health (Jersey), Group of Ethics and Humanity, Division of Society and Politics (Will), The BASE, Chapel Hill, NC 27510, USA

Author Contributions: Drs. Springer, Wang, Jersey, and Will had full access to all of the data in the study and takes responsibility for the integrity of the data and the accuracy of the data analysis.

Study concept and design: Springer, Wang, Jersey, and Will.
\end{abstract}

Acquisition, analysis, or interpretation of data: Springer, Wang, Jersey, and Will.

Drafting of the manuscript: Springer, Wang, Jersey, and Will.

Critical revision of the manuscript for important intellectual content: Springer, Wang, Jersey, and Will.

Statistical analysis: N/A.

Obtained funding: N/A.

Administrative, technical, or material support: Springer, Wang, Jersey, and Will.

Study supervision: Springer, Wang, Jersey, and Will.

Conflict of Interest Disclosures: Springer, Wang, Jersey, and Will declared no competing interests of this manuscript submitted for publication.

Funding/Support: Department support.

Role of the Funder/Sponsor: N/A.

How to Cite This Paper: Springer M, Wang F, Jersey JH, Will D. Human-animal hybrid embryo experiment: Gospel versus disaster? Sci Insigt. 2019;30(1):58-62.

Digital Object Identifier (DOI): http://dx.doi.org/10.15354/si.19.pe030.

Article Submission Information: Received, July 31, 2019; Revised: August 01, 2019; accepted: August 02, 2019. 


\section{REFERENCES}

1. Ansede M. Spanish scientists create human-monkey chimera in China. El Pais, Last access date: 08 August, 2019;

https://elpais.com/elpais/2019/07/31/i nenglish/1564561365_256842.html

2. First human-monkey chimera raises concern among scientists. The Guardian, Last access date: $08 \mathrm{Au}$ gust, 2019;

https://www.theguardian.com/science/ 2019/aug/03/first-human-monkeychimera-raises-concern-amongscientists

3. Wu J, Platero-Luengo A, Sakurai M, Sugawara A, Gil MA, Yamauchi T, Suzuki K, Bogliotti YS, Cuello C, Morales Valencia M, Okumura D, Luo J, Vilariño M, Parrilla I, Soto DA, Martinez CA, Hishida T, Sánchez-
Bautista S, Martinez-Martinez ML, Wang $\mathrm{H}$, Nohalez A, Aizawa $\mathrm{E}$, Martinez-Redondo P, Ocampo A, Reddy $P$, Roca J, Maga EA, Esteban CR, Berggren WT, Nuñez Delicado E, Lajara J, Guillen I, Guillen P, Campistol JM, Martinez EA, Ross PJ, Izpisua Belmonte JC. Interspecies chimerism with mammalian pluripotent stem cells. Cell 2017; 168(3):473486.e15.4.

4. Mummery CL, Roelen BA. Stem cells: Cloning human embryos. Nature 2013; 498(7453):174-175.

5. Breakthrough as scientists grow sheep embryos containing human cells. The Guardian, Last access date: 08 August, 2019; https://www.theguardian.com/science/ 2018/feb/17/breakthrough-as- scientists-grow-sheep-embryoscontaining-human-cells

6. Cyranoski D. Japan approves first human-animal embryo experiments. Nature 2019; Last access date: 08 August, 2019; https://www.nature.com/articles/d415 86-019-02275-3

7. Ministry OKs study to create human pancreas in rats and mice. The Asahi Shimbun, Last access date: $08 \mathrm{Au}$ gust, 2019;

http://www.asahi.com/ajw/articles/AJ2 01907250051.html

8. Human Fertilisation and Embryology Act 2008. UK Public General Acts, Last access date: 08 August, 2019; https://www.legislation.gov.uk/ukpga/ $2008 / 22 /$ section $/ 54$ ?view=plain 